\title{
Re-Defining Polyphony in Media Text for Public Relations Discursive Practices in Organization
}

\author{
Ana-Maria Teodorescu, PhD \\ Senior Lecturer in Media Studies \\ Faculty of Letters, Department of Communication Studies, Communication and Public Relations \\ University of Bucharest, Romania
}

\begin{abstract}
The research explores the new media tools manifested in communication and public relations discursive practices in organization, marked by Bahtinian polyphony in media relations texts. The study of organization theory can be defined, analyzed and evaluated as dialogic organization constructed in and by dialogues as discursive practices [Hatch 2006, Grunig, 2002, Castells 2011]. Redefining polyphony consists in analyzing the original definition as "one self - concept is formed part from the social relationship we have with others and from others' responses to what we say and do.......Because the self is constructed out of our need to balance on our own needs with those of others, the self is necessarily dialogic or make in concert with others". [Bahtin, 1981] But having the keys for reading the self - concept as the social identity of an organization, the social relationships with others, namely the public(s) as groups of interests validated in the public sphere, and the roles and relations starting from the organization to and from the public(s). Thus evaluating the main levels offered by the framework in organization, the current research has identified: the intentional level created in the communicative contract by the organization in the context the new media have been used; the impact upon the public(s) - audience and/or communities throughout the means of new media and social media, analyzing their posts, comments; the rules of structuring the sequential configuration of the messages in media text as dialog, trilog or polilog in the polyphony of discursive media relations practices in organization's site, blog, social media units-Facebook, Twitter, You Tube.
\end{abstract}

Keywords: polyphony, media text, new media, organizational discursive practices, media relations, public relations 